\title{
Comparative Study of Differences between Chinese and American E-commerce Enterprises
}

\author{
Shao Peng \\ Business School of Yunnan Normal University, Kunming, Yunnan, 650106
}

Keywords: E-commerce Enterprises, Chinese and American, Comparative Study

\begin{abstract}
E-commerce is the third industrial revolution in the history of mankind following the agricultural revolution and the industrial revolution - the business revolution. At present, there are millions of Internet companies in the world, and hundreds of millions of Internet users. As the largest developing country in the world, China is using modern science and technology such as information technology and e-commerce to integrate with traditional businesses, and vigorously promote the development of the national economy and the enhancement of comprehensive national strength. China's development needs to learn from and refer to foreign advanced experience, while the United States is the first choice for reference. It is necessary to find out the gap, analyze the reasons, propose countermeasures, and catch up. The purpose of this paper is to find out the gap between China and the United States from the perspectives of culture, economy, technology, management, education and application through a series of comparisons between Chinese and American e-commerce, then analyze the reasons for the formation of gaps, and put forward countermeasures and measures for better development of e-commerce.
\end{abstract}

\section{Introduction}

At the beginning of the new year, people all over the world seem to be indulging in "buy and buy". After experiencing a crazy big promotion, the US released "Black Friday" (specifically, the Christmas promotion in American shopping malls, named after the red record deficit in the book, black record, meaning the business is profitable) consumption data The Chinese media is very proud. Compared with the past "Single Day" buyers and the "Double Twelve" mobile payment feast, the US "Black Friday" looks really "piece of cake." However, the comparison that only stays at the level of the transaction does not make much sense. What really deserves attention is the gap between different e-commerce sales models and marketing paths.

\section{Different trends in the development of China-US e-commerce industry}

The market research organization SHOPPERTRAK statistics show that on the "Black Friday" on November 28, 2014, the sales of large traditional traditional shopping malls in the United States was 910 million US dollars, and the total retail sales of core network platforms was 2.3 billion US dollars, totaling 11.4 billion US dollars. When the world's largest IPO companies landed in the sensitive period of the United States, the capital market could easily compare this number with the Chinese "Single Day" on the other side of the ocean. Although Chinese official and industry institutions did not give the amount of retail transactions on November 11th, only the Alibaba family's statistics seem to be enough to show good performance - 57.1 billion yuan in daily trading volume, 9.3 billion US dollars! This means that the total daily trading volume of large-scale e-commerce platforms in the United States is only a quarter of that of Alibaba. The total daily trading volume of large traditional traditional shopping malls in the United States lags behind Alibaba's 200 million US dollars. Since the e-commerce enterprises such as Jingdong Mall, Gome, Suning, Vipshop, Jumeiyou and others have not released the final transaction amount, the industry has roughly statistics, and their overall contribution is close to 10 billion yuan. In terms of trading volume, Chinese e-commerce has beaten large online and offline channels in the United States. In the industry, it is more like a small-scale centralized confrontation between China and the United 
States in the new economic model, and behind the data, what is the difference between the Chinese and American e-commerce marketing models? Comparing the main differences between China and the US e-commerce model, people find that the American model is more pioneering; while Chinese e-commerce companies focus on practicality and have a more immediate impact on the national economy. Focusing on the new economic model with e-commerce as the mainstay, it is not difficult to find that the United States has the world's top Internet companies, from the old Yahoo, Google, Apple to the network of upstart Facebook, Twitter, all of them, but carefully analyzed It can be found that in addition to Amazon, eBay and Apple, most of the outstanding US technology companies are more like a technical laboratory, full of all kinds of whimsy, trying to change the world in various ways, but for business value. Realizing, how to promote the transformation of traditional business models, seems to be not the most concerned. In retrospect, the mode of operation of Chinese e-commerce, from the platform of the dominant level of Ali (Tmall, Taobao, Alipay, etc.), to the second echelon of Jingdong Mall, Dangdang, No. 1 shop, and even deep controversy, precarious group purchase And taxi software companies are well versed in the "pull economy" approach, and its operating model has a far greater impact on profitability than its American counterparts. Of course, China also has instrumental platforms, such as Tencent and Baidu in BAT. However, these two giants are also accelerating how to plan to connect with commercial operations, and then build a huge $\mathrm{O} 2 \mathrm{O}$ industrial chain. In addition, the "second echelon" in the Qiqiu 360, Xiaomi Technology, etc., are also launching "docking" plans . After the difference in the mode of operation of e-commerce between China and the United States, the difference between e-commerce management and the eco-environment system is reflected. It can be seen that the openness of the Alibaba platform and the integration of resources outside the "Single Day" battlefield can almost be said to have reached a pervasive situation. Throughout the means of market development, the details have already reflected the overall orientation. different. Pattern differences are related to the realization of business value. When people think that Tencent, Alibaba, and Baidu have been involved in various fields and have been "all-in-one", they have clearly been intertwined with the lives of countless citizens and cannot be separated. This penetration and pulling of the real economy is by no means a laboratory-based network platform. It has been noticed that the Western industry, which has always advocated substantive data, seems to be stunned by the huge consumption drivers of Chinese e-commerce "small partners". But beyond the simple data comparison, they seem to need to further understand the true power of China's new economic model represented by Ma Yun. Taking Alibaba's IPO as an example, the understanding of the US industry and capital markets after their listing is showing a gradual deepening trend.

\section{The internal driving force of the development of China's e-commerce industry}

The difference between China-US e-commerce model development is also reflected in the difference in the speed of the retail business moving to the e-commerce platform. The retail industry is closely related to mass consumption, and its activity is more reflective of the decline of the overall economic situation. The speed of its migration to the line shows the potential consumption of the people. In view of the economic weakness, the US energy consumption in 2014 has not really recovered. According to data released by the American Retail Association, retail sales in the US fell by $11 \%$ on the Black Friday after Thanksgiving in 2014, from $\$ 57.4$ billion in 2013 to $\$ 50.9$ billion. In fact, as China's economic growth slows down gradually, the data of domestic physical retailing is not worth optimistic, but the growth of China's e-commerce platform sales is really amazing. Even the huge giants like Tmall and Taobao can achieve a year-on-year increase of $57.7 \%$. Other platforms with smaller bases are more insane, and the increase of $300 \%$ to $400 \%$ is completely unnecessary. Compared with the US e-commerce website in the same period, Amazon and eBay's year-on-year growth rates were only $242 \%$ and $26.9 \%$ respectively. Of course, this is by no means that China's retail industry has surpassed the United States as a whole, but it reflects from one aspect how powerful the e-commerce marketing model is to stimulate Chinese consumer behavior, reflecting the Chinese e-commerce market in the past decade. And build ecological phase results. In the United States, the consumer market is becoming more mature. Even if the e-commerce 
marketing method has a negative effect on the US real economy, its ability to pull is very limited.

In addition, mobile consumption has become a major mainstream, and it has gradually reflected the growing maturity of China's Internet infrastructure. The United States is a big Internet country, and its basic services are more open, but even in the public spaces of many core cities, the coverage is not satisfactory. China's wireless communications infrastructure is a global extension, but it has an advantage. According to the data, as of 2014, more than 400 cities in China have invested in smart city construction, especially in first-tier cities such as Beishangguang and coastal developed areas, in the wave of construction of fiber-to-the-home, broadband cities, wireless cities, and triple play. Under the surging, a good network coverage and wireless access environment are formed. In the development of different Internet economies, there are also differences in the population base, manufacturing capacity, and offline resource richness that are easily overlooked. These factors are the most basic, but they are always easy to be ignored. The reason is: China's Internet in the past few years, especially the e-commerce industry has been "deified", but in the end, it is still based on China's real economy. If there is no population of 1.3 billion, if there is no huge manufacturing advantage and there is no "world factory" role for supplying countless commodities to the world, China will never give birth to a trillion GMV (Gross Merchandise Volume) volume in 15 years. Alibaba.

\section{China's e-commerce industry development}

When a series of data comes out, the entire Internet industry should first be grateful to the hundreds of millions of Chinese people and the real economy. It is true that the latter has a difficult life, but it is the parents of countless Internet companies. The so-called "traffic" of Internet companies is actually based on the efforts of hundreds of surnames and Chinese manufacturing companies. The United States has a population of 300 million, not too small. However, in the global manufacturing division, limited to cost factors and market factors, its manufacturing industry is mainly concentrated in the high-precision field. For this reason, a set of technical control systems for developing countries has been established, often in the name of intellectual property. The protection of reality. In addition, although the United States still attracts a large number of export commodities from all over the world, the financial crisis has changed the habit of Americans to eat and eat food to a certain extent, thus inhibiting some consumption. Comparing the above factors, we will find out what exactly is disguised as a "consumerized" China. In the "light" manufacturing area close to the people's livelihood, China is like a fish, and based on this, it continues to penetrate into the high-end manufacturing industry. This provides a wealth of offline resources for Chinese e-commerce companies. A large amount of consumption data is the reflection of this basic condition. In short, as long as people believe that the Chinese economy will continue to move forward and there will be no major fluctuations, then, to a large extent, the exploitation of offline resources will determine the future of China's Internet beyond the United States. This is the soil for the continued growth of Chinese business enterprises in the future. After the scale of the platform reaches a larger level, the ecosystem of Alibaba, Tencent and Baidu will be more abundant and deeper, and it will be in line with China Minsheng. The national economy is more closely integrated. This kind of connection that carries the national economy and people's livelihood is heavy and trivial. It is definitely not a confrontation between the "Black Friday" and "Single Day" of the Cavaliers. It happened after China became the world's second largest economy and the average purchasing power surpassed the United States. At the same time, it coincides with the listing of Chinese e-commerce concept stocks such as Alibaba, Jingdong Mall and Jumei Youpin, which are listed in the US capital market. The "blowout" phenomenon will stimulate the US counterparts in the future, and may gradually be reflected in the micro-industry competition in the future. Perhaps in the name of "trade protection", perhaps in the form of direct commercial competition, in general, Chinese e-commerce companies The non-market competition factors facing the international market may gradually emerge. In fact, American retailers have begun to express their concern for Alibaba. According to Reuters, Alliance for Main Street Fairness, a group of companies such as Best Buy, Target and Jessie Penny, asked the US Congress to cancel special taxes on online retailers such as 
Alibaba on weekend TV and radio advertisements. Concessions, and alarmist "Ali, a sudden rise in the army, will make local retailers completely annihilated."

\section{Conclusion}

There are still many potential problems in China Telecom's business. Recently, Forbes magazine raised some questions about China's e-commerce data. In fact, the data on short-term promotions cannot explain that the Chinese retail industry has defeated the United States as a whole, and the gap is still very large. It can only be said that the e-commerce economy has become a key force in China's transformation and upgrading and overtaking in corners.

\section{Acknowledgements}

Practice Facilities Development of Cross-border Electronic Commerce between China and South East Asia Countries, Ministry of Education Industry-University Cooperation Program for Collaborative Education, 2017.

Practice Curriculum Construction and Reform of Cross-border Electronic Commerce Between China and South East Asia, Ministry of Education Industry-University Cooperation Program for Collaborative Education, 2017.

Program Construction and reform of Increasing Capacity to Serve the Industry, Undergraduate Teaching Quality and Teaching Reform Project in Colleges and Universities of Yunnan Provincial Department of Education, 2015.

\section{References}

[1] Wei Wei. The role of e-commerce in the US economy [J]. American Studies, 2000 (4): 123 145.

[2] Zhang Chu. Analysis of American Electronic Commerce Law [J]. Law Science, 2000 (2): 99 106.

[3] Song Yuping. E-commerce legal competition between the United States and the European Union [J]. SAR Economics, 2007 (12): 97 - 99.

[4] Wang Liwu, Yang Liu. Analysis of the E-commerce Terms of the US Free Trade Agreement [J]. Asia-Pacific Economy, 2013 (6): 45 - 50.

[5] Chen Wei. Progress in International Negotiation of Digital Trade Liberalization and Its Enlightenment to China [J]. Journal of Shanghai University of International Business and Economics, 2015 (3). 